\title{
Testing a Smartphone App (Young with Diabetes) to Improve Self-Management of Diabetes Over 12 Months: Randomized Controlled Trial
}

Pernille Castensøe-Seidenfaden ${ }^{1}, \mathrm{MD}, \mathrm{PhD}$; Gitte Reventlov Husted ${ }^{1}, \mathrm{RN}, \mathrm{MScN}, \mathrm{PhD}$; Andreas Kryger Jensen ${ }^{2,3}$, $\mathrm{PhD}$; Eva Hommel ${ }^{4}$, MD, DMSc; Birthe Olsen ${ }^{5}, \mathrm{MD}$; Ulrik Pedersen-Bjergaard ${ }^{6}, \mathrm{MD}$, DMSc, Professor; Finn Kensing ${ }^{7}$, DSc, Professor; Grete Teilmann ${ }^{1}$, MD, PhD

\footnotetext{
${ }^{1}$ Nordsjællands Hospital, Pediatric and Adolescent Department, University of Copenhagen, Hillerød, Denmark

${ }^{2}$ Institute of Public Health, Biostatistics, University of Copenhagen, Copenhagen, Denmark

${ }^{3}$ Nordsjællands Hospital, Department of Clinical Research, University of Copenhagen, Hillerød, Denmark

${ }^{4}$ Steno Diabetes Center, Copenhagen, University of Copenhagen, Gentofte, Denmark

${ }^{5}$ Herlev Hospital, Pediatric and Adolescent Department, University of Copenhagen, Herlev, Denmark

${ }^{6}$ Nordsjællands Hospital, Department of Cardiology, Nephrology, and Endocrinology, University of Copenhagen, Hillerød, Denmark

${ }^{7}$ Department of Computer Science, University of Copenhagen, Copenhagen, Denmark
}

\section{Corresponding Author:}

Pernille Castensøe-Seidenfaden, MD, PhD

Nordsjællands Hospital

Pediatric and Adolescent Department

University of Copenhagen

Dyrehavevej 29, 1511

Hillerød, 3400

Denmark

Phone: 4548294650

Fax: 4548293034

Email: pernille.castensoee-seidenfaden@regionh.dk

\section{Abstract}

Background: Young people often struggle to self-manage type 1 diabetes during the transition from childhood to adulthood. Mobile health (mHealth) apps may have the potential to support self-management, but evidence is limited and randomized controlled trials are needed.

Objective: We assessed whether the mHealth app "Young with Diabetes" improved young people's self-management measured by glycated hemoglobin $\left(\mathrm{HbA}_{1 \mathrm{c}}\right)$ and three self-reported psychometric scales.

Methods: Young people (14-22 years) with inadequate glycemic control and their parents were enrolled in a randomized controlled trial and assigned either to Young with Diabetes and usual care (Young with Diabetes group) or to usual care alone (control). Young with Diabetes use was monitored; functions included a chat room, contact the health care provider, reminders, tips, information about the diabetes department and type 1 diabetes topics, carbohydrate counting, and a parents' section. Outcomes included $\mathrm{HbA}_{1 \mathrm{c}}$ and three self-reported psychometric scales: Perceived Competence in Diabetes Scale; Health Care Climate Questionnaire; and Problem Areas In Diabetes care survey. Data were collected at baseline and at 2, 7, and 12 months.

Results: A total of 151 young people were randomized (Young with Diabetes group=76, control=75) and 49 parents agreed to participate. At 12 months, $\mathrm{HbA}_{1 \mathrm{c}}$ was significantly higher $(4.1 \mathrm{mmol} / \mathrm{mol} ; 0.4 \%)$ in the Young with Diabetes group, compared to the control group $(P=.04)$; this finding did not occur when comparing app users (Young with Diabetes use $\geq 5$ days) with nonusers. Young people used Young with Diabetes on a mean of 10.5 days. They spent the most time chatting about alcohol and searching for information about sex. Most young people and half of the parents reported that Young with Diabetes helped them. More than $80 \%$ would recommend Young with Diabetes to peers.

Conclusions: Young with Diabetes did not improve $\mathrm{HbA}_{1 \mathrm{c}}$, but it may be a useful complement to self-management. Qualitative evaluation is needed to explore benefits and shortcomings of Young with Diabetes. Health care providers should address young 
peoples' knowledge about sensitive topics, provide them with peer support, and be aware of parents' need for information about how to support

Trial Registration: ClinicalTrials.gov NCT02632383; https://clinicaltrials.gov/ct2/show/NCT02632383 (Archived by WebCite at http://www.webcitation.org/6zCK2u7xM)

(JMIR Mhealth Uhealth 2018;6(6):e141) doi: 10.2196/mhealth.9487

\section{KEYWORDS}

mHealth; randomized controlled trial; self-management; diabetes; young people; transition

\section{Introduction}

\section{Background}

As young people with type 1 diabetes (T1DM) grow up, they are expected to assume responsibility for their disease self-management [1]. This includes daily insulin dosage, glucose measurements, and carbohydrate counting to meet the recommended target for glycemic control [2]. However, young people often struggle to achieve adequate glycemic control [3], risking early onset of long-term complications [4]. Parents are key players in supporting young people in self-managing T1DM, but they are often faced with stress and frustration [5] and request guidance on how to support their children [6].

Self-management is defined as an individual's ability to manage the symptoms and the consequences of living with a chronic condition, including treatment, physical, social, and lifestyle changes [7]. In young people, self-management is a gradual process of acquiring necessary skills and knowledge, with parents as consultants [1].

Mobile health (mHealth) apps present unique opportunities to engage young people in self-management by providing information and optimizing communication with health care providers [8]. Recent studies among adults show promising results. A systematic review assessed the effectiveness of self-management apps in long-term conditions and found that six of nine studies significantly improved outcomes [9]. Another systematic review of 12 randomized controlled trials (RCTs) demonstrated a significant reduction of glycated hemoglobin $\left(\mathrm{HbA}_{1 \mathrm{c}}\right)$ in adults (particularly with type 2 diabetes) allocated to app-based interventions to support diabetes self-management [10].

However, limited evidence exists that mHealth apps can improve young peoples' self-management [11]. Only three mHealth apps for young people with T1DM have been evaluated. Frøisland et al [12] tested a digital diabetes diary in a three-month prospective cohort study. At a mandatory consultation, the diary was discussed, and patients and providers reflected on its recordings ( $n=12$; ages 13-19). Berndt et al [13] tested an app to collect data and provide clinical support in a four-week RCT $(n=68$; ages 8-18). Finally, Goyal et al [14] tested an mHealth app in a 12-month RCT ( $n=92$; ages 12-15). The app facilitated feedback on the transfer of blood glucose readings from a glucometer, rewarding action. The three studies found no improvement in $\mathrm{HbA}_{1 \mathrm{c}}$ compared to the control group. However, one study [14] found a statistically significant association between increased self-monitored blood glucose and improved
$\mathrm{HbA}_{1 \mathrm{c}}$. Unfortunately, comparability is limited by the small number of existing studies and differences in intervention design. As the number of mHealth apps rapidly increases, a pressing need arises for more RCTs to assess the impact of mHealth apps among young people and their parents [15].

\section{Young with Diabetes - The mHealth App}

The mHealth app, Young with Diabetes (YWD), was developed in 2014 and 2015 in a mixed-methods design based on a participatory approach, with the aim of supporting young people and parents in T1DM self-management. Usability was tested in think-aloud tests and by a mail panel, and feasibility was tested for five weeks by young people and health care providers. The development is detailed elsewhere [16]. YWD is based on the premise that providing a platform for young people to access information and support from peers, parents, and health care providers will improve their self-management skills. YWD comprises eight main functions (Multimedia Appendix 1) described in the following: (1) My Page enables users to contact their health care provider and write notes, (2) My Department provides information about the diabetes department, (3) Chat Room is an opportunity to chat with peers, (4) Carbohydrate Counting provides information on how to count carbohydrates, (5) Information about... provides information about multiple T1DM-topics, such as obtaining a drivers' license, (6) Tips Package enables users to receive daily T1DM tips, (7) To Parents provides parents with information about how to support their teen, and (8) Reminder Function allows users to set reminders for self-management tasks.

The aim of this study was to test whether YWD improved self-management, measured by $\mathrm{HbA}_{1 \mathrm{c}}$ and three psychometric scales, among young people with T1DM, compared with usual outpatient care.

\section{Methods}

\section{Design, Sample, and Setting}

A 12-month, open, parallel RCT was conducted. Young people were eligible for the study if they satisfied the following conditions: (1) they had been diagnosed with T1DM for more than one year, (2) received diabetes care at one of three pediatric or three adult outpatient clinics (Multimedia Appendix 2), (3) were 14 to 22 years of age, (4) had a $\mathrm{HbA}_{1 \mathrm{c}} \geq 64 \mathrm{mmol} / \mathrm{mol}$ $(8 \%)$ at their last visit and an average $\mathrm{HbA}_{1 \mathrm{c}}>58 \mathrm{mmol} / \mathrm{mol}$ $(7.5 \%)$ at the last three visits prior to invitation, (5) did not attend appointments with a psychiatrist or psychologist, (6) they spoke and understood Danish, and (7) did not participate in other diabetes intervention studies. Parents were invited to 
participate if their child was randomized to the YWD group and if they spoke and understood Danish.

\section{Recruitment Procedures}

Young people and parents were recruited from November 2015 to March 2016. They received an invitation letter, followed by a phone call to answer any questions. If young people were interested, a one-hour meeting was scheduled to complete written consents and randomization. Participants were digitally randomized in a 1:1 allocation ratio either to YWD and usual care (YWD group) or usual care alone (control). They were stratified by department in random permuted blocks of two and four. Blinding was not possible.

\section{Intervention}

After randomization, young people and parents downloaded YWD on their smartphone or tablet during a 10-minute initial face-to-face or telephone guidance session provided by the first author. The parents received the same version of YWD except for the Chat Room, which was only available for young people. Young people were encouraged to use YWD as a stand-alone resource and in collaboration with their parents and health care providers. They received no prompts to use YWD. The control group received only usual outpatient care, which consisted of quarterly clinic visits (measuring $\mathrm{HbA}_{1 \mathrm{c}}$, adjusting insulin and receiving guidance on carbohydrate counting).

Physicians, nurses, and dieticians provided the YWD intervention as part of usual outpatient care and saw participants from both the YWD and control groups. No extra time was allocated for the YWD intervention. Health care providers attended YWD training: a one-hour introduction to the app followed by two roleplaying scenarios with a colleague or the first author acting as young patients [16].

The first author offered monthly visits to health care providers to address technical issues and refresh training in app use; a telephone hotline was available for technical difficulties. The app content did not change during the study.

\section{Outcome Measures}

Outcomes data were collected at baseline and two months, seven months, and 12 months after YWD use began. The primary outcome of $\mathrm{HbA}_{1 \mathrm{c}}$ was measured by a single automated glycohemoglobin analyzer (Tosoh) at Nordsjællands Hospital. Three psychometric self-reported scales measured the secondary outcome of the development of self-management skills. Perceived competence at managing diabetes was measured by the five-item Perceived Competence in Diabetes Scale (PCD) [17]. The degree to which participants experienced their health care provider to be autonomy-supportive in providing general treatment was measured using the five-item Health Care Climate Questionnaire (HCCQ) [17]. The perceived burden of diabetes-related problems was assessed using the 20-item Problem Areas in Diabetes care survey (PAID-20) [18]. Severe hypoglycemic episodes (low blood glucose levels requiring assistance from another person) and acute diabetes-related hospitalizations were self-reported.

\section{Sociodemographic Items and Young with Diabetes-Specific Questions}

Sociodemographic characteristics (gender, age, height, weight, age at diabetes onset, occupation, family structure, comorbidity, insulin regime, weekly blood glucose measurements, transfer to adult care, smoking, and alcohol use) were self-reported. Responses to YWD-specific questions, such as "Has YWD helped you?" and "Would you recommend it to peers?" were self-reported using yes/no response options.

The psychometric scales, sociodemographic items, and YWD-specific questions were compiled into an electronic questionnaire. Face validity was tested in six young people before the trial start; no changes were required.

YWD users were defined as those who had used YWD on at least five days. The cutoff of five days was set to be sure the participants used the app more than the four times where they were paid a visit from the data collector (baseline, 2, 7, and 12 months). YWD use was documented by log data as time, date, and action (view, update, create, delete). Page hits were defined as the number of "clicks" within a function. Technical issues were noted.

\section{Power Estimation}

Sample size estimation was based on $\mathrm{HbA}_{1 \mathrm{c}}$. A minimum of 52 participants per group was necessary to detect a difference of $5.5 \mathrm{mmol} / \mathrm{mol}(0.5 \%)$ in $\mathrm{HbA}_{1 \mathrm{c}}$ at $80 \%$ power with $5 \%$ significance level, a standard deviation in the outcome variable of 0.5 , and a 2-tailed significance test. To compensate for potential dropouts, a $25 \%$ adjustment was made, resulting in a target sample size of 65 subjects per group.

\section{Statistical Analysis}

Baseline data were described by mean and standard deviation (continuous variables) and frequencies and proportions (categorical variables). In accordance with the CONSORT guidelines [19], hypothesis tests for baseline differences were not performed.

The primary intention-to-treat analysis, comparing groups at 12 months, was performed by a linear regression model adjusting for baseline values and diabetes department. Due to stratified randomization, the department was included in the regression model as a categorical covariate [20].

The effect of YWD depends on use. Consequently, the CONSORT-EHEALTH checklist [21] recommends a sub-group analysis comparing users with nonusers, equivalent to an as-treated analysis. YWD use is a post-randomization variable, and the possibility that several unmeasured factors affected both the probability of noncompliance with the intervention and glycemic control confounds the as-treated analysis. We, therefore, focused on estimating the complier average causal effect of YWD [22]. The analysis compared the effect of the intervention among compliers (the observed YWD users and those from the control group who would have been YWD users had they been assigned to the YWD group) and non-compliers (the observed YWD non-users and those from the control group who would have used YWD less than 5 days had they been assigned to the YWD group) [22]. The causal effect of YWD 
on $\mathrm{HbA}_{1 \mathrm{c}}$ at 12 months among compliers was estimated by the expectation-maximization algorithm assuming normally distributed outcomes in each of the principal strata under one-sided noncompliance. This estimate was adjusted for baseline $\mathrm{HbA}_{1 \mathrm{c}}$ and department. Baseline variables were included as covariates for the probability of compliance with the treatment allocation in a latent logistic regression model.

Secondary analyses of outcomes $\left(\mathrm{HbA}_{1 \mathrm{c}}, \mathrm{PCD}, \mathrm{HCCQ}\right.$ and PAID) over time were performed using a constrained mixed model incorporating all measurement periods [23]. Confidence intervals were calculated using normal approximation. The number of acute hospitalizations and severe hypoglycemic episodes was compared by logistic regression after dichotomizing outcomes into zero or one or more events.

Analyses were performed by a statistician blinded to group assignment using $\mathrm{R}$ version 3.3.3 and Mplus7. A value of $P$ $\leq .05$ was considered to be statistically significant.

\section{Ethical Considerations}

YWD complies with regulations for protecting personal health information. A code was required to access YWD in addition to user name and password. Written informed consent was obtained from young people and parents, and parental consent was required for participants younger than 18 years. The study was approved by the Danish Data Protection Agency (no. 04015 NOH-2015-031) and performed in accordance with ethical recommendations of Helsinki Declaration. Ethical approval by Research Ethics Committee was not necessary (Ref.no. 14013934). The study is registered at ClinicalTrials.gov (NCT02632383). The RCT is reported in accordance with the CONSORT-EHEALTH guidelines for improving and standardizing evaluation reports of Web-based and mobile health interventions (Multimedia Appendix 3 shows the CONSORT-EHEALTH checklist [21])

\section{Results}

\section{Overview}

A total of 852 young people were assessed for eligibility, of whom 701 were excluded (Figure 1). In total, 126 young people declined to participate because they were too busy $(n=64)$, were not interested in the research project $(n=29)$, did not want to focus on diabetes $(n=11)$, did not feel they needed the app $(n=10)$, had no reason $(n=9)$, or due to illness $(n=3)$. A total of 151 young people ( $54 \%$ female) were randomized to the YWD group $(n=76)$ or control group $(n=75)$; of these, 148 (YWD=75, control=73) completed follow-up assessments, yielding a retention rate of $98 \%$.

Participants were enrolled at their homes $(n=121)$, school $(n=10)$, hospital $(n=9)$, café $(n=4)$ or by phone $(n=7)$.

\section{Baseline Characteristics}

Participants' mean age was 17.6 (SD 2.6) years, and their mean duration of T1DM was 8.0 (SD 4.5) years (Table 1). One third $(n=42,28 \%)$ had at least one comorbidity, and half $(n=70,46 \%)$ of the participants' parents were divorced. A total of 49 parents participated, representing 40 (53\%) young people in the YWD group.

\section{Outcome Measures}

\section{Glycated Hemoglobin}

Mean baseline $\mathrm{HbA}_{1 \mathrm{c}}$ (Figure 2 and Table 2) was $81.1 \mathrm{mmol} / \mathrm{mol}$ (SD 18.0) or $9.6 \%$ (SD 1.6) in the YWD group and 76.2 $\mathrm{mmol} / \mathrm{mol}$ (SD 14.9) or $9.1 \%$ (SD 1.4) in the control group. This difference was not significant $(P=.07)$. At the 12-month follow-up, mean $\mathrm{HbA}_{1 \mathrm{c}}$ was $81.4 \mathrm{mmol} / \mathrm{mol}$ (SD 18.8) or $9.6 \%$ (SD 1.7) in the YWD group and $73.9 \mathrm{mmol} / \mathrm{mol}$ (SD 12.6) or $8.9 \%$ (SD 1.2) in the control group. The intention-to-treat-analysis, comparing the two groups at 12 months, showed a significant difference in glycemic control $(P=.04)$, with the control group having a $4.1 \mathrm{mmol} / \mathrm{mol}(95 \%$ CI 0.3-7.9) or $0.4 \%$ (95\% CI 0.0-0.7) lower mean $\mathrm{HbA}_{1 \mathrm{c}}$ after adjusting for baseline values. After including all follow-up periods in the mixed model, this difference was $4.3 \mathrm{mmol} / \mathrm{mol}$ (95\% CI $0.7-8.0$ ) or $0.4 \%$ (95\% CI 0.1-0.7, P=.02). Despite randomization, the YWD group included more females. This difference was not significant $(P=.37)$; adjusting for gender in the intention-to-treat analysis did not change the results.

\section{Effect of App Use on Glycated Hemoglobin}

The as-treated analysis, comparing YWD users with nonusers, yielded a non-significant difference in $\mathrm{HbA}_{1 \mathrm{c}}$ at 12 months $(P=.67)$, with the control group having a $0.9 \mathrm{mmol} / \mathrm{mol}(95 \%$ $\mathrm{CI}-3.1$ to 4.9$)$ or $0.1 \%(95 \% \mathrm{CI}-0.3$ to 0.4$)$ lower mean $\mathrm{HbA}_{1 \mathrm{c}}$. The complier average causal effect of YWD, comparing the effect of the intervention among compliers and non-compliers (please refer to the Statistical Analysis section for further details), yielded a non-significant difference of $3.9 \mathrm{mmol} / \mathrm{mol}$ (95\% CI -0.7 to 8.9 ) or $0.4 \%$ (95\% CI -0.1 to $0.8, P=.11)$ in $\mathrm{HbA}_{1 \mathrm{c}}$, favoring the control group. No baseline covariates were significantly associated with the probability of compliance with the treatment allocation (Multimedia Appendix 4). However, a negative effect on the probability of compliance to the treatment allocation was related to comorbidity, divorced parents, severe hypoglycemic episodes during the previous 12 months, forgetting insulin, smoking, alcohol-drinking intake and skipping school. A positive effect on the probability of compliance with the treatment allocation was related to the number of glucose measurements last week, acute hospitalizations, insulin pump and the female gender.

\section{Self-Reported Self-Management of Type 1 Diabetes}

As shown in Table 2, no significant effects on PCD $(P=.39)$, PAID $(P=.13)$, or HCCQ $(P=.53)$ were observed.

\section{Hypoglycemia and Hospitalizations}

Between-group differences in acute diabetes-related hospitalizations and severe hypoglycemia were not statistically significant. Seventeen (22\%) participants from the YWD group and $8(11 \%)$ participants from the control group were hospitalized for an acute event at least once during the 12-month study period. The control group had 54\% lower odds (odds ratio [OR] $0.46,95 \%$ CI $0.17-1.15, P=.10$ ) of acute hospitalization after adjusting for acute hospitalizations during the 12 months 
prior to enrollment. A total of 34 (45\%) participants in the YWD group and 29 (39\%) in the control group experienced at least one episode of severe hypoglycemia. The control group had $13 \%$ lower odds (OR $0.87,95 \%$ CI $0.43-1.75, P=.70$ ) of severe hypoglycemia, compared to YWD group, after adjusting for hypoglycemic episodes during the year prior to the study.

Figure 1. Participant flow diagram.

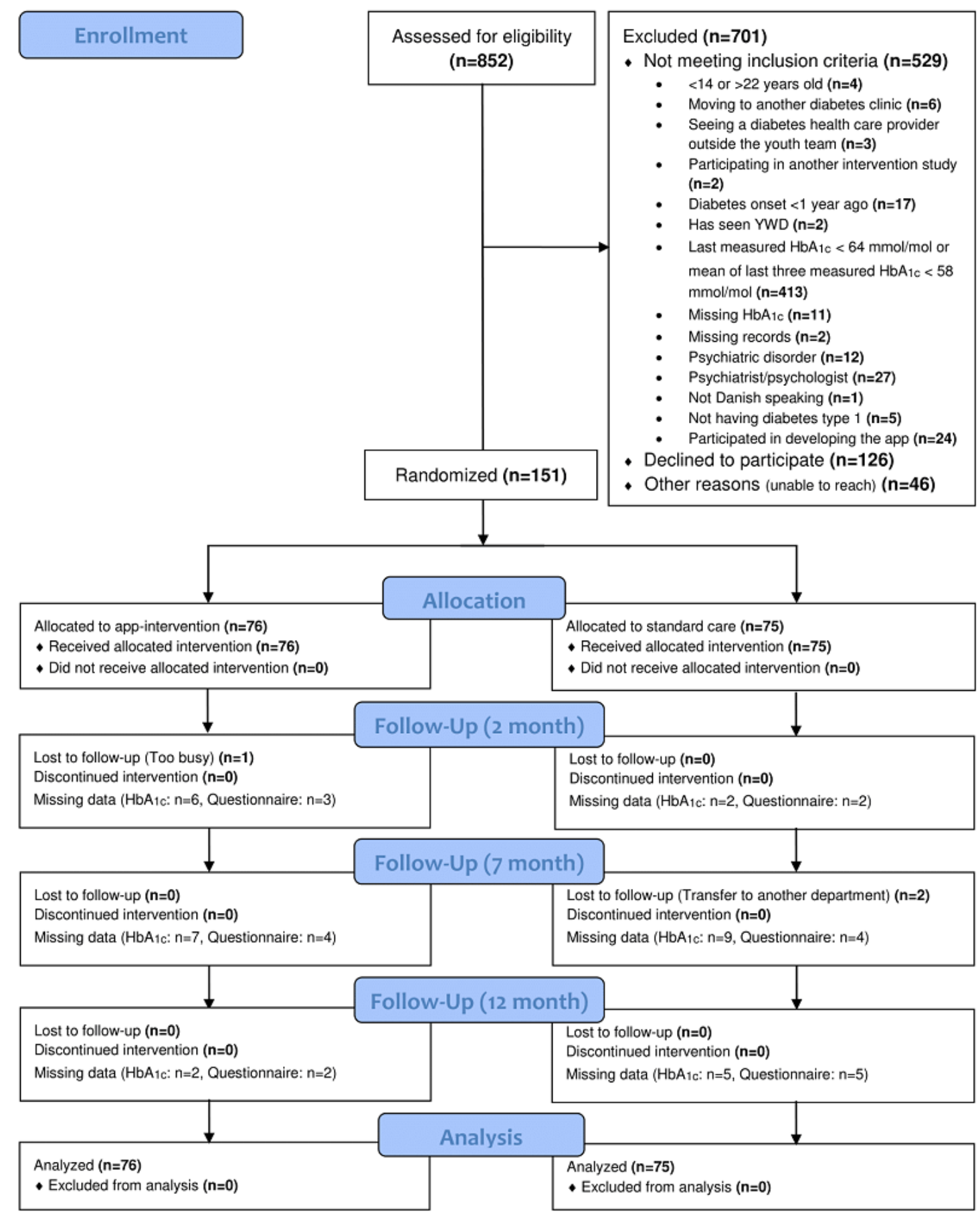


Table 1. Sample characteristics.

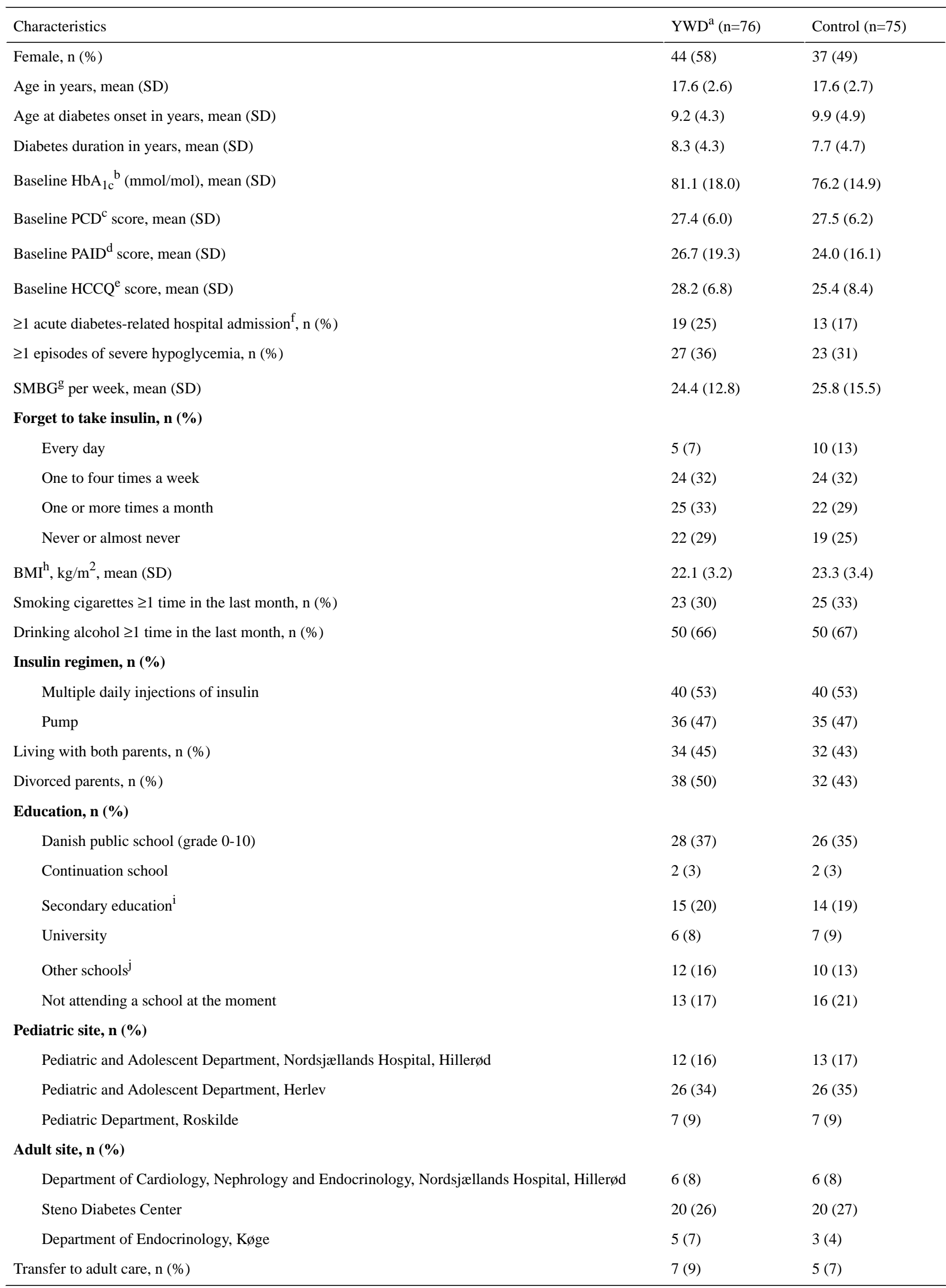




\begin{tabular}{lll}
\hline Characteristics & $\mathrm{YWD}^{\mathrm{a}}(\mathrm{n}=76)$ & Control $(\mathrm{n}=75)$ \\
\hline Comorbidity, $\mathbf{n}(\boldsymbol{\%})$ & $22(29)$ & $20(27)$ \\
$\quad$ Learning disability and/or mental health condition & $6(8)$ & $2(3)$ \\
\hline
\end{tabular}

${ }^{\mathrm{a}}$ YWD: Young with Diabetes.

${ }^{\mathrm{b}} \mathrm{HbA}_{1 \mathrm{c}}$ : glycated hemoglobin

${ }^{\mathrm{c}}$ PCD: Perceived Competence in Diabetes Scale.

${ }^{\mathrm{d}}$ PAID: Problem Areas in Diabetes Scale.

${ }^{\mathrm{e}} \mathrm{HCCQ}$ : Health Care Climate Questionnaire.

${ }^{\mathrm{f}}$ Acute hospital admission caused by hyperglycemia, ketoacidosis or hypoglycemia.

${ }^{\text {g}}$ SMBG: self-monitored blood glucose.

${ }^{\mathrm{h}}$ BMI: body mass index.

${ }^{\mathrm{i}}$ Secondary education: Gymnasium, Higher Preparatory Examination, Higher Commercial Examination Program, Higher Technical Examination Program. ${ }^{\mathrm{j}}$ Other schools, such as taking a bachelor in nursing or attending a school of crafts.

Figure 2. Mean glycated hemoglobin $\left(\mathrm{HbA}_{1 \mathrm{c}}\right)$ levels in control and Young with Diabetes (YWD) groups at 2, 7, and 12 months.

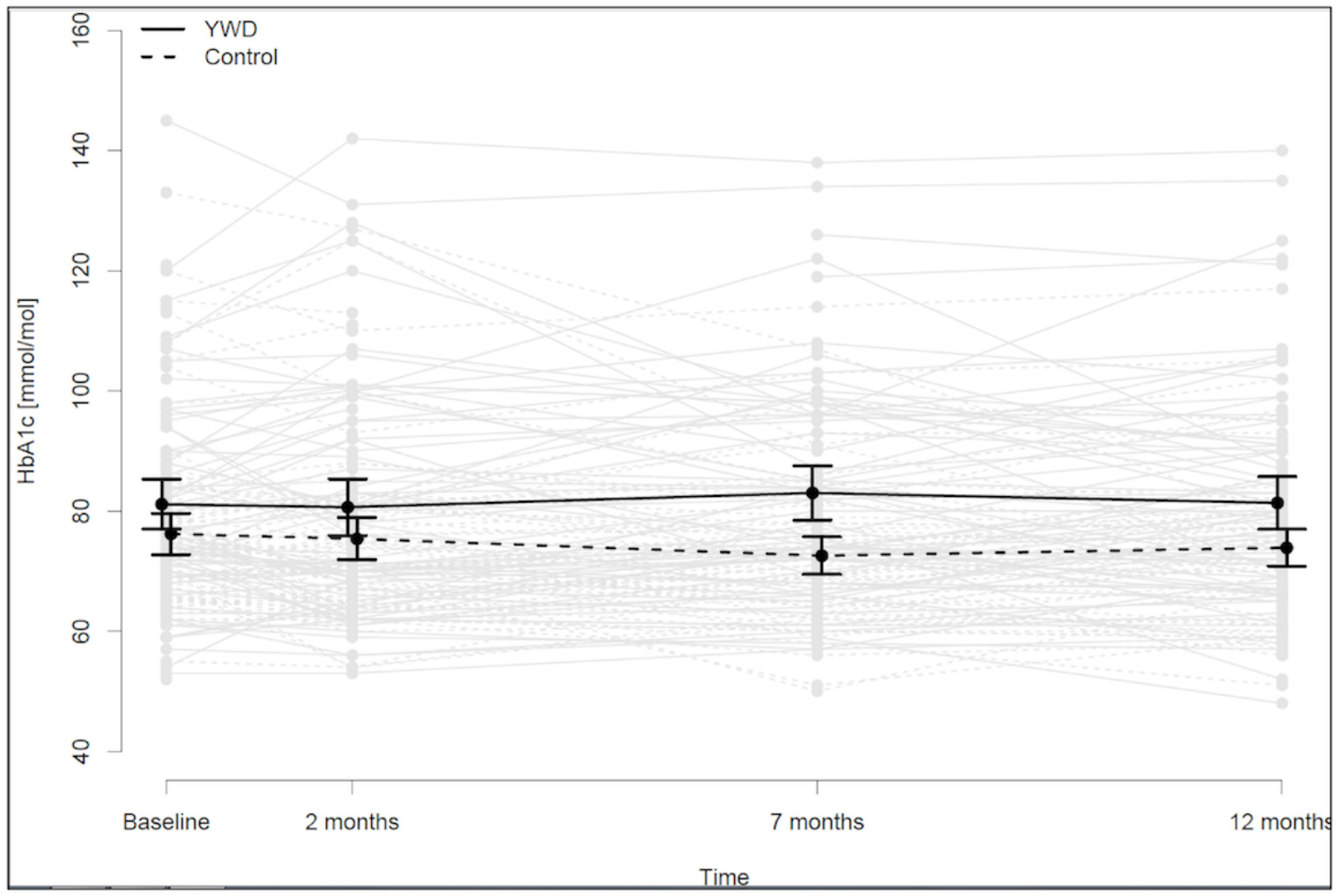


Table 2. Between-group differences in outcomes.

\begin{tabular}{|c|c|c|c|c|c|}
\hline \multirow[t]{2}{*}{ Outcome } & \multirow[t]{2}{*}{ Adjusted mean at baseline } & \multicolumn{4}{|c|}{ Control versus YWD ${ }^{\mathrm{a}}$, mean difference $(95 \% \mathrm{CI})$} \\
\hline & & 2 months & 7 months & 12 months & $P$ value $^{\mathrm{b}}$ \\
\hline $\mathrm{HbA}_{1 \mathrm{c}}{ }^{\mathrm{c}}, \mathrm{mmol} / \mathrm{mol}$ & 78.9 & $-2.8(-5.4$ to -0.3$)$ & $-6.2(-9.5$ to -2.9$)$ & $-4.3(-8.0$ to 0.7$)$ & 0.02 \\
\hline $\mathrm{HbA}_{1 \mathrm{c}}{ }^{\mathrm{c}}, \%$ & 9.4 & $-0.3(-0.5$ to 0.0$)$ & $-0.6(-0.9$ to -0.3$)$ & $-0.4(-0.7$ to 0.1$)$ & 0.02 \\
\hline $\operatorname{PCD}^{\mathrm{d}}$ score $^{\mathrm{e}}$ & 28.18 & $0.27(-1.50$ to 2.03$)$ & $-0.53(-2.55$ to 1.50$)$ & $-0.79(-2.56$ to 0.98$)$ & 0.39 \\
\hline PAID $^{f}$ score $^{e}$ & 23.68 & $-2.64(-6.17$ to 0.88$)$ & $0.96(-3.00$ to 4.91$)$ & $-3.14(-7.22$ to 0.95$)$ & 0.13 \\
\hline $\mathrm{HCCQ}^{\mathrm{g}}$ score $^{\mathrm{e}}$ & 27.10 & $-0.05(-2.44$ to 2.35$)$ & $0.04(-2.52$ to 2.61$)$ & $-0.73(-2.98$ to 1.52$)$ & 0.53 \\
\hline
\end{tabular}

${ }^{\mathrm{a}}$ YWD: Young with Diabetes.

${ }^{\mathrm{b}}$ Significance level of difference at 12 months follow-up.

${ }^{\mathrm{c}} \mathrm{HbA}_{1 \mathrm{c}}$ : glycated hemoglobin.

${ }^{\mathrm{d}}$ PCD: Perceived Competence in Diabetes Scale.

${ }^{\mathrm{e}}$ Range for PCD and HCCQ is 5-35 and the range for PAID is 0-100.

${ }^{f}$ PAID: Problem Areas in Diabetes.

g HCCQ: Health Care Climate Questionnaire.

\section{Young with Diabetes-Specific Questions}

Fifty-nine (78\%) young people and $25(51 \%)$ parents reported that YWD had helped them at least once. Most young people $(n=65,85 \%)$ and parents $(n=41,84 \%)$ reported that they would recommend YWD to peers.

\section{Young with Diabetes Use}

Young people used YWD on a mean of 10.5 days (range 1-64), while parents used YWD on a mean of 5 days (range 1-21). A total of $53(70 \%)$ young people and $19(39 \%)$ parents used YWD on at least 5 days, while $7(9 \%)$ young people and $13(27 \%)$ parents never used YWD after the introductory session. Figure 3 depicts weekly YWD activity.

In total, 71 messages were sent to $14(36 \%)$ health care providers by $15(20 \%)$ young people. The messages were primarily used to schedule visits $(n=25)$, ask treatment questions such as about insulin dose $(\mathrm{n}=24)$; discuss challenges such as eating disorders and feeling alone $(n=9)$; and provide ongoing support such as feedback on glucose measurements $(n=13)$.

A total of 103 chat-room comments were posted by 28 (37\%) young people (Multimedia Appendix 5). The majority of chat time was spent on Alcohol, Sport, and Fuck Diabetes. Fifteen (20\%) young people created reminders, and $46(61 \%)$ activated tips packages. The carbohydrate-counting quiz was initiated 68 times by $46(61 \%)$ young people. Only 7 (9\%) young people watched animations, while 18 (24\%) clicked on video self-portraits. The most popular main functions were Chat Room and My Page (Multimedia Appendix 6), and the most popular information topics were Sex, What is Diabetes?, Driver's License, and Alcohol and Party (Multimedia Appendix 7). Among parents, the most popular main functions were Information about ... and To Parents (Multimedia Appendix 6). Parents primarily approached How to Support My Teen, When My Teen turns 18, Alcohol and Party, and Being Young with Diabetes (Multimedia Appendix 7).

\section{Technical Issues}

Four major platform-specific technical issues occurred and were resolved: (1) January 2016, Android. Starting carbohydrate-counting-quiz resulted in log-off (duration=10 days, $n=1$ ), (2) March 2016, iOS. YWD could not open on some iPhone-software versions. Required re-installation (duration=10 days, $n=7$ ), (3) September 2016, Android. Unable to upload photos (duration=40 days, $n=1$ ), and (4) January 2017, iOS. YWD could not open due to update. Needed re-installation (duration=10 days, $n=14$ ). In addition, participants reported minor technical issues, such as having lost the YWD app due to new or broken phones (young people $=26$, parents $=2$ ). A total of $43(57 \%)$ young people and eight $(16 \%)$ parents reported technical issues. 
Figure 3. Number of young people who used Young with Diabetes (YWD) during the study.

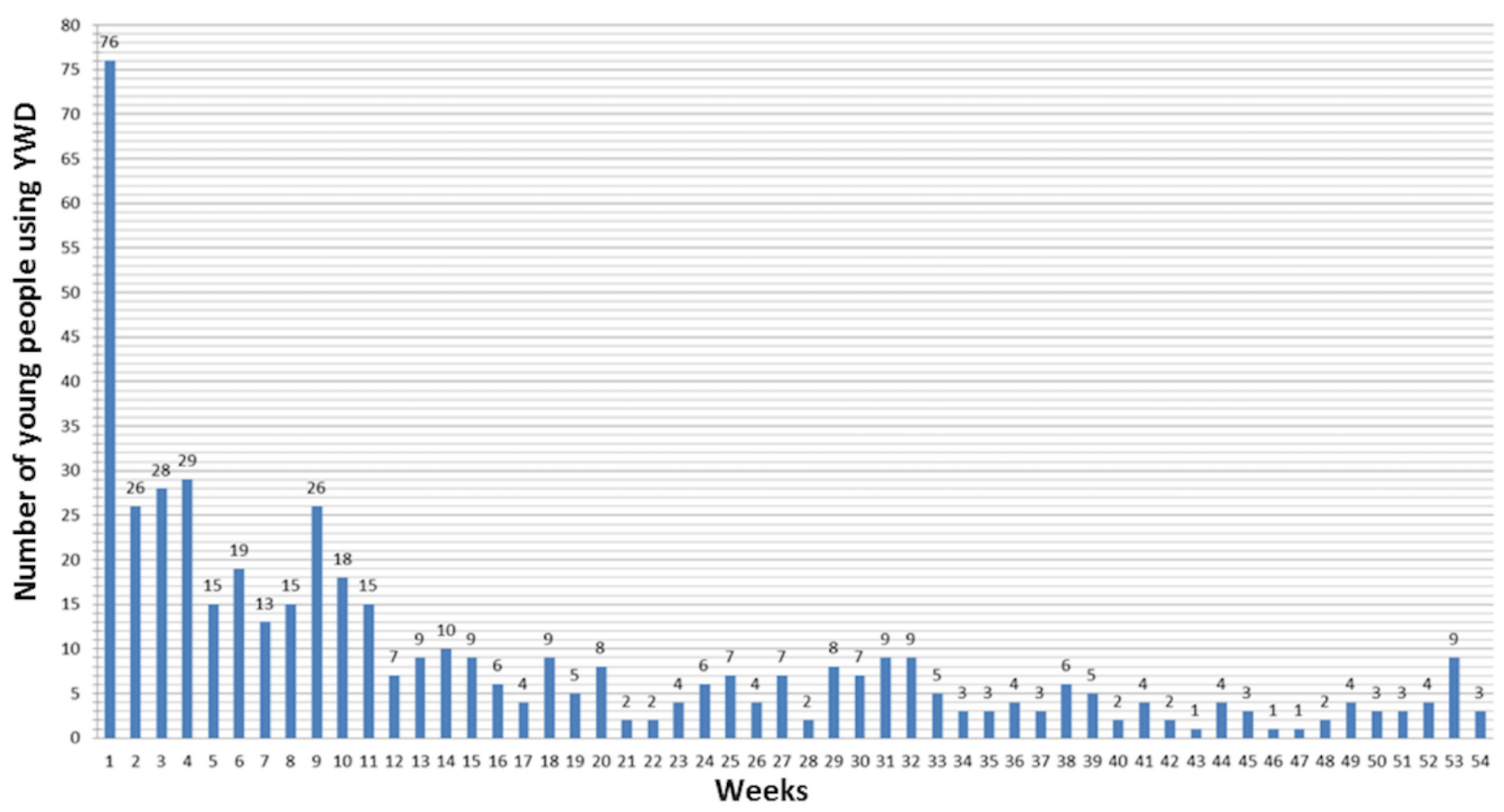

\section{Discussion}

\section{Principal Findings}

To the best of our knowledge, this is the largest RCT to date evaluating the effect of an mHealth app supporting self-management in young people with T1DM and their parents. YWD did not improve glycemic control, and the app use declined rapidly. Interestingly, most of the participants reported that YWD was helpful and that they would recommend it to others.

We can only speculate as to why $\mathrm{HbA}_{1 \mathrm{c}}$ did not improve in the YWD group. A large difference was observed between the results from the as-treated analysis and the estimate of the complier average causal effect $(0.9 \mathrm{mmol} / \mathrm{mol} \mathrm{vs} .3 .9 \mathrm{mmol} / \mathrm{mol}$, respectively). This may indicate the existence of unmeasured confounding variables influencing $\mathrm{HbA}_{1 \mathrm{c}}$ and YWD use. Health care providers play a significant role in supporting young people to self-manage [24]. However, not all health care providers feel confident using mHealth apps [25], and some may feel uncomfortable engaging with young people through technical means [26,27]. This could have influenced the effect of YWD. Unfortunately, we neither registered the young people's health care provider nor stratified at the level of the health care provider. Also, YWD training for health care providers was very brief; further training may optimize health care providers' ability to use YWD as a platform for collaborating with young people and parents. Furthermore, the use of YWD declined rapidly during the RCT (Figure 3), which may be one of the main reasons why the intervention lacked improvement of self-management. Since the participants did not use YWD for long, a mediation analysis would have been highly relevant. However, the study was an RCT designed and powered for assessing the difference in $\mathrm{HbA}_{1 \mathrm{c}}$ and therefore, we did not pursue a post-hoc analysis. This is important to address in the design of future studies.

A qualitative study by Klasnja et al [28] found that most people diagnosed with diabetes, face acute need for information about their disease and that this need becomes more intermittent afterwards. It would have been highly relevant to test YWD in a group of people newly diagnosed with T1DM. Unfortunately, $\mathrm{HbA}_{1 \mathrm{c}}$ differs and changes a lot during the time around diagnosis depending on how long (days, weeks, or months) people have had diabetes before it is diagnosed and depending on the degree of the eventual honeymoon phase. Since $\mathrm{HbA}_{1 \mathrm{c}}$ was our primary outcome, we had to be sure that we only included patients with "stable" diabetes to better identify the effect of the intervention. This challenge could be addressed in future studies by qualitative evaluation of self-management apps in people just diagnosed with diabetes.

We were unable to measure participants' eHealth skills, which may have influenced YWD use and subsequent $\mathrm{HbA}_{1 \mathrm{c}}$ levels since it is related to improved outcomes [29-31]. Furthermore, baseline $\mathrm{HbA}_{1 \mathrm{c}}$ was higher in the YWD group, which may indicate poor motivation and lack of self-management skills, which would affect the ability to use YWD and improve $\mathrm{HbA}_{1 \mathrm{c}}$ [32]. Finally, it is arguable whether a randomized trial is the optimal way to evaluate YWD. Diabetes care should be individualized [33], and mHealth apps, which evolve and are updated over time, are often incompatible with a rigid RCT study design. Furthermore, Campbell et al [34] raise doubts about RCTs as an evaluation method targeting young people in transition from childhood to adulthood due to the complex, patient-centered, evolving, and multidisciplinary nature of care. Alternative methods may be preferable, such as qualitative evaluations and interrupted time series [35]. 
Further qualitative evaluation [36] is needed to understand why most young people reported being helped by using YWD, despite failing to improve glycemic control and maintain app use. Also, successful adoption of self-management apps is hard to achieve without additional strategies for enhancing patient motivation and engaging health care providers [37]. Finally, simply knowing how often and how much young people engage with YWD by opening the app and clicking around may not be enough. Understanding and observing "effective engagement" $[38,39]$ with mHealth apps is much harder to do, and better ways need to be worked out. This should be taken into account in future studies.

Notably, the most popular app function among young people was the Chat room, where they shared experiences. The most popular topics were Alcohol and Fuck Diabetes. While few participants posted comments, most read about others' experiences. This is consistent with previous findings [40,41] and underscores the importance of online peer support to complement education and provide reassurance that lived experiences are common [42].

In contrast, more sensitive topics, such as sex, were not discussed in the chat room but were the most popular topic searched privately. Wiley et al [42] explored young adults' experiences with T1DM education and found that health care providers did not address sensitive topics such as sex. Our findings and those of Wiley et al highlight the unmet needs of young people and parents, which should be solicited and addressed regularly in clinic visits. They underscore the importance of acknowledging young peoples' need for sharing experiences with peers and providing them with opportunities to engage with peer networks. The findings also emphasize parents' need for guidance in supporting their child and the importance of addressing sensitive topics regularly.

\section{Strengths and Limitations}

Our study has several strengths. A rigorous design tested YWD in an RCT over a lengthy study period, and YWD use was logged and available for analysis. Our study had both a large sample size and a high retention rate. The high retention rate could be a result of the flexibility to collect data at young peoples' choice of place and time of day and should be considered a way to ensure high retention rates in future studies with young people.

Limitations should also be considered. It was not possible to conduct a blinded RCT $[43,44]$. Not all young people had participating parents. No clear criteria were defined for how health care providers should deliver YWD. Also, we cannot exclude the possibility of a spillover effect because the same health care professionals provided both the YWD intervention and usual care. Finally, a concern is whether $\mathrm{HbA}_{1 \mathrm{c}}$ and the three psychometric questionnaires (PCD, HCCQ, PAID-20) captured changes in self-management as intended. Our choice of scales was limited by lack of validated self-management instruments in Danish and also by the ages of the participants, spanning below and above 18 years. The outcomes were chosen based on the self-management definition [1,7] and because they have been used in similar populations testing self-management interventions $[45,46]$, increasing the comparability of our study.

\section{Conclusion}

The mHealth app YWD did not improve $\mathrm{HbA}_{1 \mathrm{c}}$, but it may be a useful tool for complementing self-management in young people with T1DM. Qualitative evaluation is needed to further explore and address benefits and shortcomings of the intervention [36]. Alternative evaluation methods should be considered when testing self-management mHealth apps among young people. Our findings highlight the importance of supplementing self-management care with peer support. Health care providers should routinely address sensitive topics and be aware of parents' need for guidance as to how to effectively support their child during the transition from childhood to adulthood.

\section{Acknowledgments}

We gratefully acknowledge all participating young people, parents and health care providers from Pediatric and Adolescent Department and Department of Cardiology, Nephrology, and Endocrinology, Nordsjællands Hospital, Pediatric and Adolescent Department, Herlev Hospital, Steno Diabetes Center, Copenhagen, Pediatric Department, Roskilde Hospital and Department of Endocrinology, Køge Hospital. This study was funded by Danish Agency for Digitisation, Centre for Telemedicine, Capital Region of Denmark and a Research Grant from Nordsjællands Hospital, Hillerød.

\section{Conflicts of Interest}

YWD was developed in cooperation with the IT enterprise Mobile Fitness A/S and the project group (including the authors). The project group owns the national rights.

\section{Multimedia Appendix 1}

Detailed description of the mHealth application Young with Diabetes.

[PNG File, 715KB-Multimedia Appendix 1]

\section{Multimedia Appendix 2}

Diabetes departments participating in the RCT. 
[PNG File, 102KB-Multimedia Appendix 2]

\section{Multimedia Appendix 3}

CONSORT-EHEALTH checklist (v1.6.1).

[PDF File (Adobe PDF File), 102KB-Multimedia Appendix 3]

\section{Multimedia Appendix 4}

Association between baseline covariates and compliance.

[JPG File, 943KB-Multimedia Appendix 4]

\section{Multimedia Appendix 5}

Use of chat room groups.

[JPG File, 1MB-Multimedia Appendix 5]

\section{Multimedia Appendix 6}

Use of main functions by young people and parents.

[ $\underline{\text { JPG File, 921KB-Multimedia Appendix 6] }}$

\section{Multimedia Appendix 7}

Use of information topics by young people and parents.

[JPG File, 1MB-Multimedia Appendix 7]

\section{References}

1. Kieckhefer GM, Trahms CM. Supporting development of children with chronic conditions: from compliance toward shared management. Pediatr Nurs 2000;26(4):354-363. [Medline: 12026469]

2. National Institute for Health and Care Excellence (NICE). Nice guidelines. Diabetes (type 1 and type 2) in children and young people: Diagnosis and management URL: https://www.nice.org.uk/guidance/ng18 [accessed 2018-05-08] [WebCite Cache ID 6zG1jjB0M]

3. Castensøe-Seidenfaden P, Jensen AK, Smedegaard H, Hommel E, Husted GR, Pedersen-Bjergaard U, et al. Clinical, behavioural and social indicators for poor glycaemic control around the time of transfer to adult care: a longitudinal study of 126 young people with diabetes. Diabet Med 2017 May;34(5):667-675. [doi: 10.1111/dme.13318] [Medline: 28099760]

4. Bryden KS, Dunger DB, Mayou RA, Peveler RC, Neil HAW. Poor prognosis of young adults with type 1 diabetes: a longitudinal study. Diabetes Care 2003 Apr;26(4):1052-1057. [Medline: 12663572]

5. Haugstvedt A, Wentzel-Larsen T, Rokne B, Graue M. Perceived family burden and emotional distress: similarities and differences between mothers and fathers of children with type 1 diabetes in a population-based study. Pediatr Diabetes 2011 Mar;12(2):107-114. [doi: 10.1111/j.1399-5448.2010.00661.x] [Medline: 20522171]

6. Akre C, Suris J. From controlling to letting go: what are the psychosocial needs of parents of adolescents with a chronic illness? Health Educ Res 2014 Oct;29(5):764-772. [doi: 10.1093/her/cyu040] [Medline: 24997206]

7. Barlow J, Wright C, Sheasby J, Turner A, Hainsworth J. Self-management approaches for people with chronic conditions: a review. Patient Educ Couns 2002;48(2):177-187. [Medline: 12401421]

8. Sawyer SM, Afifi RA, Bearinger LH, Blakemore S, Dick B, Ezeh AC, et al. Adolescence: a foundation for future health. Lancet 2012 Apr 28;379(9826):1630-1640. [doi: 10.1016/S0140-6736(12)60072-5] [Medline: 22538178]

9. Whitehead L, Seaton P. The Effectiveness of Self-Management Mobile Phone and Tablet Apps in Long-term Condition Management: A Systematic Review. J Med Internet Res 2016;18(5):e97 [FREE Full text] [doi: 10.2196/jmir.4883] [Medline: 27185295]

10. Wu Y, Yao X, Vespasiani G, Nicolucci A, Dong Y, Kwong J, et al. Mobile App-Based Interventions to Support Diabetes Self-Management: A Systematic Review of Randomized Controlled Trials to Identify Functions Associated with Glycemic Efficacy. JMIR Mhealth Uhealth 2017 Mar 14;5(3):e35 [FREE Full text] [doi: 10.2196/mhealth.6522] [Medline: 28292740]

11. Deacon AJ, Edirippulige S. Using mobile technology to motivate adolescents with type 1 diabetes mellitus: A systematic review of recent literature. J Telemed Telecare 2015 Dec;21(8):431-438. [doi: 10.1177/1357633X15605223] [Medline: 26377124] 
12. Frøisland DH, Arsand E, Skårderud F. Improving diabetes care for young people with type 1 diabetes through visual learning on mobile phones: mixed-methods study. J Med Internet Res 2012;14(4):e111 [FREE Full text] [doi: 10.2196/jmir.2155] [Medline: 22868871]

13. Berndt R, Takenga C, Preik P, Kuehn S, Berndt L, Mayer H, et al. Impact of information technology on the therapy of type-1 diabetes: a case study of children and adolescents in Germany. J Pers Med 2014;4(2):200-217. [doi: 10.3390/jpm4020200] [Medline: 25563223]

14. Goyal S, Nunn CA, Rotondi M, Couperthwaite AB, Reiser S, Simone A, et al. A Mobile App for the Self-Management of Type 1 Diabetes Among Adolescents: A Randomized Controlled Trial. JMIR Mhealth Uhealth 2017 Jun 19;5(6):e82 [FREE Full text] [doi: 10.2196/mhealth.7336] [Medline: 28630037]

15. Misra S, Lewis TL, Aungst TD. Medical application use and the need for further research and assessment for clinical practice: creation and integration of standards for best practice to alleviate poor application design. JAMA Dermatol 2013 Jun;149(6):661-662. [doi: 10.1001/jamadermatol.2013.606] [Medline: 23783150]

16. Castensøe-Seidenfaden P, Husted GR, Teilmann G, Hommel E, Olsen BS, Kensing F. Designing a Self-Management App for Young People With Type 1 Diabetes: Methodological Challenges, Experiences, and Recommendations. JMIR Mhealth Uhealth 2017 Oct 23;5(10):e124 [FREE Full text] [doi: 10.2196/mhealth.8137] [Medline: 29061552]

17. Williams GC, Freedman ZR, Deci EL. Supporting autonomy to motivate patients with diabetes for glucose control. Diabetes Care 1998 Oct;21(10):1644-1651. [Medline: 9773724]

18. Polonsky WH, Anderson BJ, Lohrer PA, Welch G, Jacobson AM, Aponte JE, et al. Assessment of diabetes-related distress. Diabetes Care 1995 Jun;18(6):754-760. [Medline: 7555499]

19. Moher D, Hopewell S, Schulz KF, Montori V, Gøtzsche PC, Devereaux PJ, et al. CONSORT 2010 explanation and elaboration: updated guidelines for reporting parallel group randomised trials. BMJ 2010 Mar;340:c869 [FREE Full text] [Medline: 20332511]

20. International Conference on Harmonisation Expert Working Group. 1999 Aug 15. Statistical principles for clinical trials URL: http://www.ich.org/fileadmin/Public Web Site/ICH Products/Guidelines/Efficacy/E9/Step4/E9 Guideline.pdf [accessed 2018-05-08] [WebCite Cache ID 6zG5wag4T]

21. Eysenbach G, CONSORT-EHEALTH Group. CONSORT-EHEALTH: improving and standardizing evaluation reports of Web-based and mobile health interventions. J Med Internet Res 2011 Dec 31;13(4):e126 [FREE Full text] [doi: 10.2196/jmir.1923] [Medline: 22209829]

22. Imbens GW, Rubin DB. Estimating Outcome Distributions for Compliers in Instrumental Variables Models. The Review of Economic Studies 1997 Oct 01;64(4):555-574. [doi: 10.2307/2971731]

23. Liang K, Zeger S. Longitudinal data analysis of continuous and discrete responses for pre-post designs. Sankhya: The Indian Journal of Statistics Series B 2000 Apr:134-148.

24. Fegran L, Hall EOC, Uhrenfeldt L, Aagaard H, Ludvigsen MS. Adolescents' and young adults' transition experiences when transferring from paediatric to adult care: a qualitative metasynthesis. Int J Nurs Stud 2014 Jan;51(1):123-135. [doi: 10.1016/j.ijnurstu.2013.02.001] [Medline: 23490470]

25. Swallow V. An exploration of mothers' and fathers' views of their identities in chronic-kidney-disease management: parents as students? J Clin Nurs 2008 Dec;17(23):3177-3186. [doi: 10.1111/j.1365-2702.2008.02642.x] [Medline: 19012785]

26. Hardoff D, Danziger Y, Reisler G, Stoffman N, Ziv A. Minding the gap: training in adolescent medicine when formal training programmes are not available. Arch Dis Child Educ Pract Ed 2009 Oct;94(5):157-160. [doi: 10.1136/adc.2008.155762] [Medline: 19770496$]$

27. Brown T. Are you a digital native or a digital immigrant? Being Client Centred in the Digital Era. British Journal of Occupational Therapy 2011 Jul;74(7):313-313. [doi: 10.4276/030802211X13099513660992]

28. Klasnja P, Kendall L, Pratt W, Blondon K. Long-Term Engagement with Health-Management Technology: a Dynamic Process in Diabetes. AMIA Annu Symp Proc 2015 Nov 05; eCollection 2015:756-765 [FREE Full text] [Medline: 26958211]

29. Koontz MB, Cuttler L, Palmert MR, O'Riordan M, Borawski EA, McConnell J, et al. Development and validation of a questionnaire to assess carbohydrate and insulin-dosing knowledge in youth with type 1 diabetes. Diabetes Care 2010 Mar;33(3):457-462 [FREE Full text] [doi: 10.2337/dc09-0390] [Medline: 20007940]

30. Wysocki T, Lochrie A, Antal H, Buckloh LM. Youth and parent knowledge and communication about major complications of type 1 diabetes: associations with diabetes outcomes. Diabetes Care 2011 Aug;34(8):1701-1705 [FREE Full text] [doi: 10.2337/dc11-0577] [Medline: 21659641]

31. Mulvaney SA, Lilley JS, Cavanaugh KL, Pittel EJ, Rothman RL. Validation of the diabetes numeracy test with adolescents with type 1 diabetes. J Health Commun 2013;18(7):795-804 [FREE Full text] [doi: 10.1080/10810730.2012.757394] [Medline: 23577642]

32. Peyrot M, Rubin RR, Lauritzen T, Snoek FJ, Matthews DR, Skovlund SE. Psychosocial problems and barriers to improved diabetes management: results of the Cross-National Diabetes Attitudes, Wishes and Needs (DAWN) Study. Diabet Med 2005 Oct;22(10):1379-1385. [doi: 10.1111/j.1464-5491.2005.01644.x] [Medline: 16176200]

33. National Institute for Health and Care Excellence (NICE). 2016. Diabetes in children and young people URL: https://www. nice.org.uk/guidance/qs125 [accessed 2017-11-09] [WebCite Cache ID 6zG52UpYF] 
34. Campbell F, Biggs K, Aldiss SK, O'Neill PM, Clowes M, McDonagh J, et al. Transition of care for adolescents from paediatric services to adult health services. Cochrane Database Syst Rev 2016 Apr 29;4:CD009794. [doi: 10.1002/14651858.CD009794.pub2] [Medline: 27128768]

35. Kumar S, Nilsen WJ, Abernethy A, Atienza A, Patrick K, Pavel M, et al. Mobile health technology evaluation: the mHealth evidence workshop. Am J Prev Med 2013 Aug;45(2):228-236 [FREE Full text] [doi: 10.1016/j.amepre.2013.03.017] [Medline: 23867031]

36. Husted GR, Weis J, Teilmann G, Castensøe-Seidenfaden P. Exploring the Influence of a Smartphone App (Young with Diabetes) on Young People's Self-Management: Qualitative Study. JMIR Mhealth Uhealth 2018 Feb 28;6(2):e43 [FREE Full text] [doi: 10.2196/mhealth.8876] [Medline: 29490897]

37. van Vugt M, de Wit M, Sieverink F, Roelofsen Y, Hendriks SH, Bilo HJG, et al. Uptake and Effects of the e-Vita Personal Health Record with Self-Management Support and Coaching, for Type 2 Diabetes Patients Treated in Primary Care. J Diabetes Res 2016;2016:5027356 [FREE Full text] [doi: 10.1155/2016/5027356] [Medline: 26955640]

38. Yardley L, Spring BJ, Riper H, Morrison LG, Crane DH, Curtis K, et al. Understanding and Promoting Effective Engagement With Digital Behavior Change Interventions. Am J Prev Med 2016 Nov;51(5):833-842. [doi: 10.1016/j.amepre.2016.06.015] [Medline: 27745683]

39. Andersen TO, Bansler JP, Kensing F, Moll J. From Prototype to Product: Making Participatory Design of mHealth Commercially Viable. Stud Health Technol Inform 2017;233:95-112. [Medline: 28125417]

40. Hanberger L, Ludvigsson J, Nordfeldt S. Use of a web 2.0 portal to improve education and communication in young patients with families: randomized controlled trial. J Med Internet Res 2013;15(8):e175 [FREE Full text] [doi: 10.2196/jmir.2425] [Medline: 23973555]

41. Kingod N, Cleal B, Wahlberg A, Husted GR. Online Peer-to-Peer Communities in the Daily Lives of People With Chronic Illness: A Qualitative Systematic Review. Qual Health Res 2017 Jan;27(1):89-99. [doi: 10.1177/1049732316680203] [Medline: 27956659]

42. Wiley J, Westbrook M, Long J, Greenfield JR, Day RO, Braithwaite J. Diabetes education: the experiences of young adults with type 1 diabetes. Diabetes Ther 2014 Jun;5(1):299-321 [FREE Full text] [doi: 10.1007/s13300-014-0056-0] [Medline: $\underline{24519150]}$

43. Wood L, Egger M, Gluud LL, Schulz KF, Jüni P, Altman DG, et al. Empirical evidence of bias in treatment effect estimates in controlled trials with different interventions and outcomes: meta-epidemiological study. BMJ 2008 Mar 15;336(7644):601-605 [FREE Full text] [doi: 10.1136/bmj.39465.451748.AD] [Medline: $\underline{\text { 18316340] }}$

44. Savović J, Jones HE, Altman DG, Harris RJ, Jüni P, Pildal J, et al. Influence of reported study design characteristics on intervention effect estimates from randomized, controlled trials. Ann Intern Med 2012 Sep 18;157(6):429-438. [doi: 10.7326/0003-4819-157-6-201209180-00537] [Medline: 22945832]

45. Sattoe JNT, Bal MI, Roelofs PDDM, Bal R, Miedema HS, van Staa A. Self-management interventions for young people with chronic conditions: A systematic overview. Patient Educ Couns 2015 Jun;98(6):704-715. [doi:

10.1016/j.pec.2015.03.004] [Medline: 25819373]

46. Husted GR, Thorsteinsson B, Esbensen BA, Gluud C, Winkel P, Hommel E, et al. Effect of guided self-determination youth intervention integrated into outpatient visits versus treatment as usual on glycemic control and life skills: a randomized clinical trial in adolescents with type 1 diabetes. Trials 2014 Aug 12;15:321 [FREE Full text] [doi: 10.1186/1745-6215-15-321] [Medline: 25118146]

\author{
Abbreviations

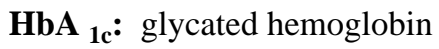 \\ HCCQ: Health Care Climate Questionnaire \\ OR: odds ratio \\ PAID: Problem Areas in Diabetes \\ PCD: Perceived Competence in Diabetes \\ RCT: randomized controlled trial \\ T1DM: type 1 diabetes \\ YWD: Young with Diabetes
}


Edited by G Eysenbach; submitted 23.11.17; peer-reviewed by S Kumar, M Grey, S Comulada, K Blondon; comments to author 01.02.18; revised version received 22.03.18; accepted 31.03.18; published 26.06.18

Please cite as:

Castensøe-Seidenfaden P, Husted GR, Jensen AK, Hommel E, Olsen B, Pedersen-Bjergaard U, Kensing F, Teilmann G

Testing a Smartphone App (Young with Diabetes) to Improve Self-Management of Diabetes Over 12 Months: Randomized Controlled Trial

JMIR Mhealth Uhealth 2018;6(6):e141

URL: http://mhealth.jmir.org/2018/6/e141/

doi: 10.2196/mhealth.9487

PMID: 29945861

CPernille Castensøe-Seidenfaden, Gitte Reventlov Husted, Andreas Kryger Jensen, Eva Hommel, Birthe Olsen, Ulrik Pedersen-Bjergaard, Finn Kensing, Grete Teilmann. Originally published in JMIR Mhealth and Uhealth (http://mhealth.jmir.org), 26.06.2018. This is an open-access article distributed under the terms of the Creative Commons Attribution License (https://creativecommons.org/licenses/by/4.0/), which permits unrestricted use, distribution, and reproduction in any medium, provided the original work, first published in JMIR mhealth and uhealth, is properly cited. The complete bibliographic information, a link to the original publication on http://mhealth.jmir.org/, as well as this copyright and license information must be included. 